\title{
Photo-generation of Heptacene in a Polymer Matrix
}

\author{
Rajib Mondal, Bipin K. Shah, and Douglas C. Neckers* \\ Center for Photochemical Sciences, Bowling Green State University, Bowling Green, OH, 43403.
}

\section{Supporting Information}

\section{Experimental Section}

Solvents and reagents were used as received from commercial suppliers. Standard grade silica gel $(60 \AA, 32-63 \mu \mathrm{m})$ and silica gel plates $(200 \mu \mathrm{m})$ were purchased from Sorbent Technologies. Reactions that required anhydrous conditions were carried out under argon in oven-dried glassware. Organic solvents were either spectroscopic grade or purified by distillation and dried before use using proper drying reagents.

Mass spectra were recorded on Shimadzu GCMS-QP5050A instrument equipped with a direct probe (ionization $70 \mathrm{eV}$ ). Matrix assisted laser desorption ionization (MALDI) spectra were obtained using Bruker Daltonic Omniflex ${ }^{\circledR}$ instrument $\left(\mathrm{N}_{2}\right.$ laser, $337 \mathrm{~nm}$ ). A Bruker spectrometer (working frequency $300.0 \mathrm{MHz}$ for $1 \mathrm{H}$ ) was used to record NMR spectra. Absorption and fluorescence spectra were recorded on a Shimadzu UV-2401 spectrophotometer and a Fluorolog®-3 spectrometer, respectively. All measurements were carried out at room temperature unless otherwise specified.

\section{Synthesis.}

2,3-Dibromonaphthalene (3). It was prepared following a literature procedure. ${ }^{14} \mathrm{Mp} 136$ ${ }^{\circ} \mathrm{C} ;{ }^{1} \mathrm{H}$ NMR (300 MHz, $\left.\mathrm{CDCl}_{3}\right) 7.51$ (m, 2H), $7.72(\mathrm{~m}, 2 \mathrm{H}), 8.15$ (s, 2H); ${ }^{13} \mathrm{C}$ NMR (300 $\mathrm{MHz}, \mathrm{CDCl}_{3}$ ) 121.96, 126.86, 127.18, 132.25, 133.06; mass spectrum (GC-MS) $\mathrm{m} / \mathrm{z} \mathrm{M}^{+}$ 126(95), 205(30), 20(30), 284(50), 286(100), 288(50). 
Bicyclo[2,2,2]oct-2,3,5,6,7-pentaene (4). It was prepared following a literature procedure. ${ }^{15} \mathrm{Mp} 97-98{ }^{\circ} \mathrm{C} ;{ }^{1} \mathrm{H}$ NMR $\left(300 \mathrm{MHz}, \mathrm{CDCl}_{3}\right) 3.851$ (m, 2H), $4.9(\mathrm{~s}, 4 \mathrm{H}), 5.25$ (s, 4H), 6.36 (m, 2H); ${ }^{13} \mathrm{C}$ NMR (300 MHz, $\mathrm{CDCl}_{3}$ ) 53.15, 104.13, 132.34, 144.27; mass spectrum (GC-MS) $m / z \mathrm{M}^{+}$104(80), 115(70), 141(100), 156(96).

6,7,8,15,16,17-Hexahydro-7,16-diethenoheptacene (5). $n$-Butyllithium $(2.5 \mathrm{M}$ in hexane) (3.6 $\mathrm{mL}, 9 \mathrm{mmol})$ was added drop-wise under an argon atmosphere to a suspension of $\mathbf{3}(1.79 \mathrm{~g}, 6.25 \mathrm{mmol})$ and $4(0.48 \mathrm{~g}, 3.07 \mathrm{mmol})$ in $125 \mathrm{~mL}$ of dry toluene cooled to $-50--60^{\circ} \mathrm{C}$. The mixture was allowed to stir for three hour at $-50--60^{\circ} \mathrm{C}$. Then the temperature was allowed to very slowly increase to r. t. and excess of $n$-butyllithium was quenched by methanol. The product was concentrated on a rotary evaporator. GC/MS analysis of the product showed it to be a mixture of mono-adduct $(6,7,10,11$ tetrahydro-7,10-dietheno.8,9-dimethylene-tetracene) and bi-adduct (5). The latter was separated from the former by column chromatography (silica gel). Elution was started with $2 \%$ (vol.) of dichloromethane in hexane and ended with $50 \%$ (vol.) of dichloromethane in hexane. The mono-adduct eluted first, which was followed by elution of the bi-adduct (5). The separated solvent fractions were evaporated to isolate the monoadduct $(0.30 \mathrm{~g}$, yield $35 \%)$ and $\mathbf{5}(0.67 \mathrm{~g}$, yield $53 \%)$.

6,7,10,11-Tetrahydro-7,10-dietheno.8,9-dimethylene-tetraene (mono-adduct). Mp 206 $207^{\circ} \mathrm{C}$; ${ }^{1} \mathrm{H}$ NMR (300 MHz, $\mathrm{CDCl}_{3}$ ) 3.75 (s, 4H), 4.014 (m, 2H), 4.89 (s, $2 \mathrm{H}$ ), 5.1 (s, 2 $\mathrm{H}), 6.52(\mathrm{~m}, 2 \mathrm{H}) 7.36(\mathrm{~m}, 2 \mathrm{H}), 7.61(\mathrm{~s}, 2 \mathrm{H}), 7.71(\mathrm{~m}, 2 \mathrm{H}) ;{ }^{13} \mathrm{C} \mathrm{NMR}(300 \mathrm{MHz}$, $\mathrm{CDCl}_{3}$ ) 31.70, 52.47, 101.66, 125.15, 126.79, 127.06, 132.22, 132.87, 133.77, 134.03, 144.05; mass spectrum (DIP-MS) $\mathrm{m} / z \mathrm{M}^{+}$133(60), 178(85), 228(65), 252(50), 267(75), 282(100); HRMS (EI) $m / z, 282.1409\left(\mathrm{M}^{+}\right)$, calcd $m / z 282.1409$.

6,7,8,15,16,17-Hexahydro-7,16-diethenoheptacene (5). Mp 268 - 269 $\mathrm{C} ;{ }^{1} \mathrm{H}$ NMR (300 $\mathrm{MHz}, \mathrm{CDCl}_{3}$ ), 3.81 (s, $\left.8 \mathrm{H}\right), 4.411$ (m, $\left.2 \mathrm{H}\right), 6.91$ (m, $\left.2 \mathrm{H}\right), 7.35$ (m, $\left.4 \mathrm{H}\right), 7.61$ (s, $\left.4 \mathrm{H}\right)$, $7.71(\mathrm{~m}, 4 \mathrm{H}) ;{ }^{13} \mathrm{C} \mathrm{NMR}\left(300 \mathrm{MHz}, \mathrm{CDCl}_{3}\right.$ ) 33.21, 54.47, 125.05, 126.77, 127.04, 132.24, 133.27, 139.44, 140.04; mass spectrum (DIP-MS) m/z $\mathrm{M}^{+}$378(10), 389(10), 408(100); HRMS (EI) $m / z, 408.1879\left(\mathrm{M}^{+}\right)$, calcd $m / z 408.1878$.

7,16-Dihydro-7,16-diethenoheptacene (6). 5 (1.13 g, $2.77 \mathrm{mmol})$ and chloranil (1.35 g, $5.49 \mathrm{mmol}$ ) were taken in a round bottom flask containing $110 \mathrm{~mL}$ of dry toluene and refluxed for $2 \mathrm{hrs}$. The reaction mixture was kept for overnight at r. t., when a part of the 
product $(0.46 \mathrm{~g})$ precipitated out. It was separated by filtration followed by washing with hexane. The filtrate was concentrated on a rotary evaporator and subjected to column chromatography [silica gel, $20 \%$ (vol.) dichloromethane in hexane] to yield 6 ( $0.45 \mathrm{~g}$, yield 81\%). $\mathrm{Mp}>300^{\circ} \mathrm{C}$ (decomp.), ${ }^{1} \mathrm{H}$ NMR (300 MHz, $\mathrm{CDCl}_{3}$ ) 5.32 (m, $2 \mathrm{H}$ ), 7.04 (m, 2H), 7.40 (m, 4 H) 7.873 (s, 4 H), 7.927 (m, 4 H), 8.281 (s, 4 H); ${ }^{13} \mathrm{C}$ NMR (300 MHz, $\left.\mathrm{CDCl}_{3}\right)$ 49.83, 120.97, 124.94, 125.62, 127.98, 130.59, 131.68, 137.51, 140.87; mass spectrum (DIP-MS) $m / z \mathrm{M}^{+}$201(80), 378(15), 404(100); HRMS (EI) $\mathrm{m} / z$ $404.1556\left(\mathrm{M}^{+}\right.$), calcd $m / z$ 404.1565.

7,16-Dihydro-19,20-dihydroxy-7,16-ethanoheptacene (7). To a solution of 4methylmorpholine $N$-oxide $(0.336 \mathrm{~g}, \mathrm{mmol})$ in $200 \mathrm{~mL}$ of acetone, $2.5 \%$ (w) solution of osmium tetroxide in $t$-butanol $(0.5 \mathrm{~mL}, \mathrm{mmol})$ was added under an argon atmosphere and stirred for $10 \mathrm{~min}$ at $\mathrm{r}$. t. Then, a suspension of $6(0.4 \mathrm{~g}, 1.0 \mathrm{mmol})$ in $100 \mathrm{~mL}$ of acetone was added and the mixture continued to stir for $48 \mathrm{hrs}$. Sodium dithionite $(0.5 \mathrm{~g})$ was added to the reaction mixture, which was stirred for another 20 min to yield a heterogeneous solution. It was then filtered through a pad cerite, followed by washing with acetone. The filtrate was then concentrated to about $100 \mathrm{~mL}$, which resulted offwhite precipitate. The precipitate was filtered and subjected to column chromatography (silica-gel). Impurities were washed with 5-50\% (vol.) of chloroform in hexane and finally 7 was eluted with chloroform. After evaporating the solvent, pure $7(0.35 \mathrm{~g}$, yield $83 \%$ ) was isolated as white solid. $\mathrm{Mp}>300^{\circ} \mathrm{C}$ (decomp.); ${ }^{1} \mathrm{H}$ NMR (300 $\mathrm{MHz}, \mathrm{CDCl}_{3}$ ) 2.33 (s, broad, $2 \mathrm{H}$, quenched with $\left.\mathrm{D}_{2} \mathrm{O}\right), 4.33(\mathrm{~s}, 2 \mathrm{H}) 4.70(\mathrm{~s}, 2 \mathrm{H}), 7.45(\mathrm{~m}, 4 \mathrm{H}), 8.00$ (m, $8 \mathrm{H}), 8.38$ (m, $4 \mathrm{H}) ;{ }^{13} \mathrm{C}$ NMR (300 MHz, $\mathrm{Me}_{2} \mathrm{SO}_{-} \mathrm{d}_{6}$ ) 51.47, 67.88, 123.06, 124.42, 125.56, 125.66, 125.80, 126.03, 128.37, 131.10, 131.24, 131.36, 131.55, 137.64, 138.39; mass spectrum (DIP-MS) $m / z \mathrm{M}^{+} 189$ (68), 378 (100), 438 (6); HRMS (EI) $m / z 438.1627$ $\left(\mathrm{M}^{+}\right)$, calcd $m / z$ 438.1620.

7,16-Dihydro-7,16-ethanoheptacene-19,20-dione (2). Trifluoroacetic acid (4.2 mL) was added drop wise to a stirring solution of dry-dimethylsulfoxide (DMSO, $2.4 \mathrm{~mL}$ ) in 50 $\mathrm{mL}$ of dichloromethane kept at $-78{ }^{\circ} \mathrm{C}$ under an argon atmosphere. After 15 min of stirring, a solution of $7(0.30 \mathrm{~g}, 0.68 \mathrm{mmol})$ in $2.4 \mathrm{~mL}$ of DMSO in $30 \mathrm{~mL}$ of dichloromethane was added very slowly. The resulted mixture was continued to stir for $90 \mathrm{~min}$, followed by drop-wise addition of triethyl amine $(5 \mathrm{~mL})$. After stirring for 
another 90 min at $-78{ }^{\circ} \mathrm{C}$ under inert atmosphere, the reaction mixture was allowed to warm to $r$. t. The resulting bright yellow solution was then extracted with dichloromethane, followed by washing the organic extract with water. Further purification was achieved by column chromatography (silica gel, dichloromethane) to obtain pure $2(0.155 \mathrm{~g}$, yield $51 \%)$ as bright yellow solid. ${ }^{1} \mathrm{H}$ NMR $\left(300 \mathrm{MHz}, \mathrm{CDCl}_{3}\right)$ 5.398 (s, 2 H), 7.492 (dd, 4 H), 8.00 (dd, 4 H), 8.117 (s, 4 H), 8.435 (s, 4 H); ${ }^{13} \mathrm{C}$ NMR (300 MHz, $\mathrm{CDCl}_{3}$ ) 61.14, 125.54, 126.08, 126.57, 128.17, 131.19, 131.37, 132.24, 185.80; mass spectrum (DIP-MS) m/z M+ 189 (69), 190 (14), 378 (100), 379 (33), 434 (3); HRMS (EI) $m / z 434.1324\left(\mathbf{M}^{+}\right)$, calcd 434.1307.

\section{Scheme S1.}

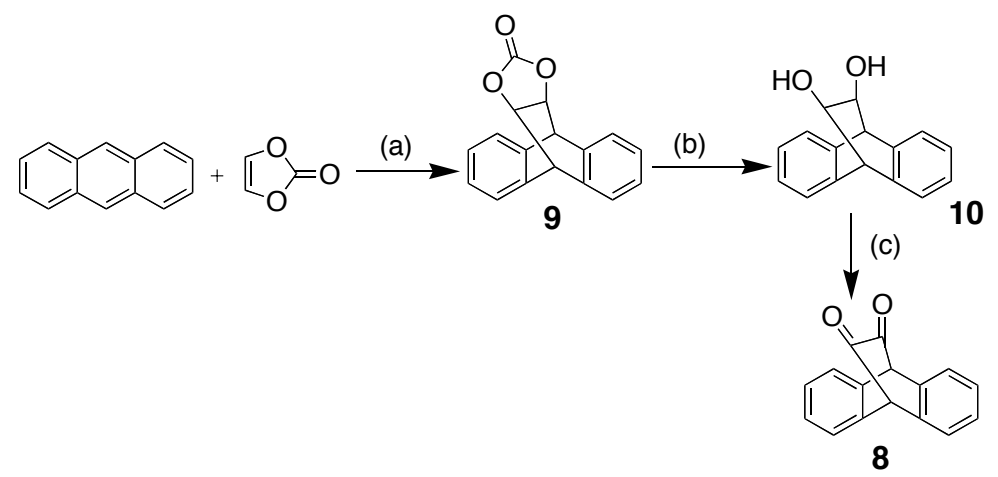

Reagents and conditions: (a) vinylene carbonate, toluene, $180{ }^{\circ} \mathrm{C}, 3$ days, $90 \%$; (b) $\mathrm{NaOH}$, Dioxane, reflux, 2 hr., 100\%; (c) DMSO, TFAA, $\mathrm{CH}_{2} \mathrm{Cl}_{2},-78{ }^{\circ} \mathrm{C}, 3 \mathrm{hr}$., $65 \%$.

9,10-Dihydro-11,12-dihydroxy-9,10-ethanoanthracene (10). Anthracene (1.05 g, 6 mmol) and vinylene carbonate $(0.5 \mathrm{~mL}, 9.5 \mathrm{mmol})$ were taken in a $30 \mathrm{~mL}$ steel-bomb reactor containing dry toluene $(25 \mathrm{~mL})$. The mixture was heated at $180{ }^{\circ} \mathrm{C}$ and stirred for 3 days. After cooling to room temperature, the reactor was opened very carefully and the produced gel-type material was evaporated under reduced pressure in a rotary evaporator to obtain a white solid. The solid was further purified by column chromatography (silica gel). The residual reactants were washed with $20 \%$ (v) of dichloromethane in hexane. Finally, the product was eluted with dichloromethane. Evaporation of the solvent yielded 9 (1.41 g, yield 90\%). IR $1791 \mathrm{~cm}^{-1} ;{ }^{1} \mathrm{H}$ NMR (300 MHz, $\left.\mathrm{CDCl}_{3}\right) 4.7(\mathrm{~d}, \mathrm{~J}=1.5 \mathrm{~Hz}, 2 \mathrm{H})$, 
$4.88(\mathrm{~m}, 2 \mathrm{H}), 7.25\left(\mathrm{~m}, 5 \mathrm{H}, \mathrm{CDCl}_{3}\right), 7.385(\mathrm{~m}, 4 \mathrm{H})$; mass spectrum (GC-MS) $\mathrm{m} / z \mathrm{M}^{+}$ 178(100), 264(2).

$9(2.0 \mathrm{~g}, 7.56 \mathrm{mmol})$ was taken in 1,4-dioxane $(90 \mathrm{~mL})$ in a round bottom flask, to which $30 \mathrm{~mL}$ of $4 \mathrm{~N} \mathrm{NaOH}$ (aq.) was added. The reaction mixture was refluxed for $2 \mathrm{hrs}$ under an argon atmosphere. After cooling the reaction mixture to $\mathrm{r}$. t., the product was extracted with chloroform. The organic extract was then dried over $\mathrm{Na}_{2} \mathrm{SO}_{4}$. Removal of the solvent yielded 10 (1.80 g, yield 100\%). IR 3300-3500 $\mathrm{cm}^{-1}$ (broad), ${ }^{1} \mathrm{H}$ NMR (300 MHz, $\mathrm{CDCl}_{3}$ ) 2.091 (s, $2 \mathrm{H}$ ), 4.067 (s, $2 \mathrm{H}$ ), 4.423 (s, 2 H), 7.19 (m, 4 H), 7.35 (m, 4 H), mass spectrum (DIP-MS) 178(100), HRMS (EI) m/z $238.0994\left(\mathrm{M}^{+}\right.$), calcd $m / z$ 238.0994.

9,10-Dihydro-9,10-ethanoanthracene-11,12-dione (8). A synthetic procedure similar to that used for 2 was employed to synthesize 10 from 9. The yield was 65\%. ${ }^{1} \mathrm{H}$ NMR (300 $\left.\mathrm{MHz}, \mathrm{CDCl}_{3}\right) 5.003$ (s, $\left.2 \mathrm{H}\right), 7.38$ (dd, 4H), 7.48 (dd, $4 \mathrm{H}$ ); ${ }^{13} \mathrm{C}$ NMR (300 MHz, $\mathrm{CDCl}_{3}$ ) 60.02, 126.32, 129.40, 134.87, 183.71; mass spectrum (GC-MS) m/z $\mathrm{M}^{+} 89$ (15), 178 (100), 234 (2); HRMS (EI) $m / z, 234.0683\left(\mathrm{M}^{+}\right)$, calcd $\mathrm{m} / \mathrm{z} 234.0681$.

\section{Irradiation in solution.}

Dilute solution of $10\left(1.5 \times 10^{-3} \mathrm{ML}^{-1}\right)$ in toluene was taken in $4 \mathrm{~mL}$ quartz cuvette. It was irradiated at $395 \mathrm{~nm}$ using a UV-LED lamp and UV-vis spectra were recorded every 5-10 min. Similarly, a dilute solution of $2\left(1.0 \times 10^{-3} \mathrm{M}^{-1} \mathrm{~L}^{-1}\right)$ in toluene was taken and made air-free by freeze-pump-thaw method. This solution was then used to for photoirradiation.

\section{Preparation of PMMA films.}

A saturated solution of photoprecursors ( $\mathbf{2}$ or $\mathbf{1 0})$ in dichloromethane was mixed with a solution of PMMA in acetonitrile. Few drops of the mixture was placed on a quartz disc and dried for overnight. The films showing absorbance $0.2-0.4$ were used for irradiation.

\section{MALDI of heptacene from the thin film.}

A thin PMMA film of $\mathbf{2}$ was irradiated for $30 \mathrm{~min}$. A portion of the film was scratched from the quartz substrate and dissolved in degassed dichloromethane. A MALDI spectrum was immediately recorded using a dithranol matrix (Figure S8). 


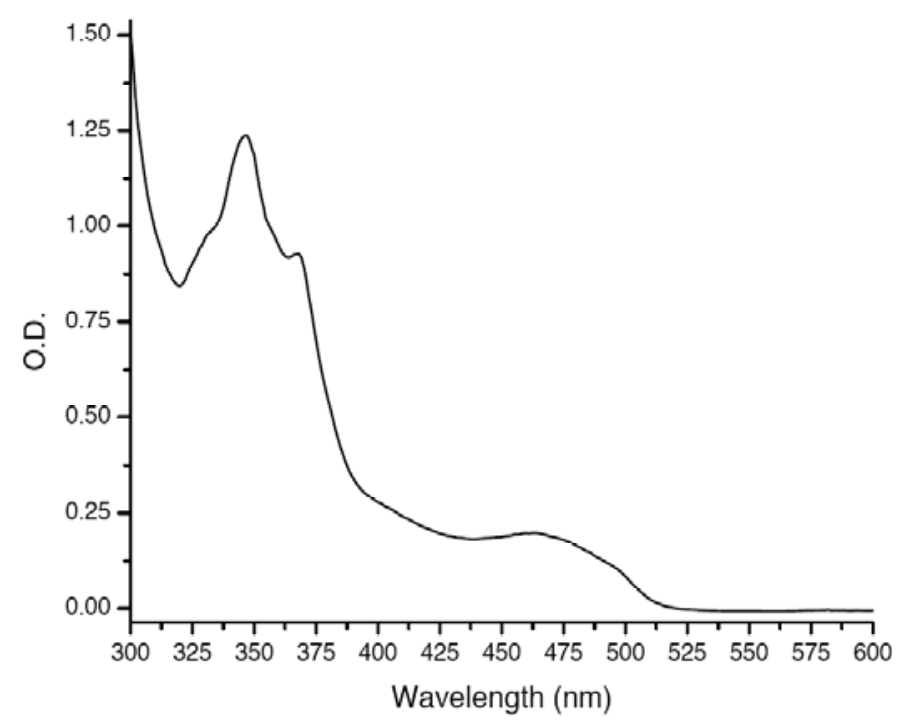

Fig. S1. UV-vis absorption spectrum of 2 in toluene.

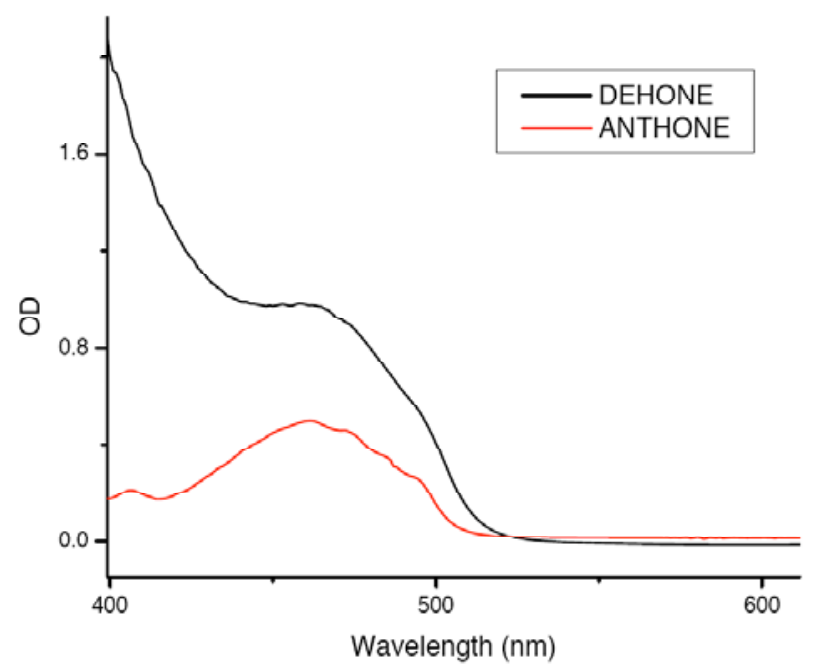

Fig. S2. UV-vis absorption spectra of $\mathbf{1 0}$ (red line) and $\mathbf{2}$ (black line) in the PMMA films.

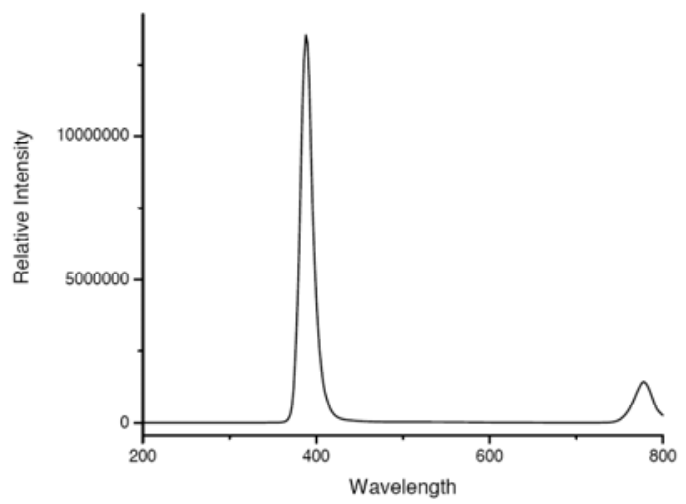

Fig. S3. The emission spectrum of the array of UV-LED's (395 nm) used for irradiation. 


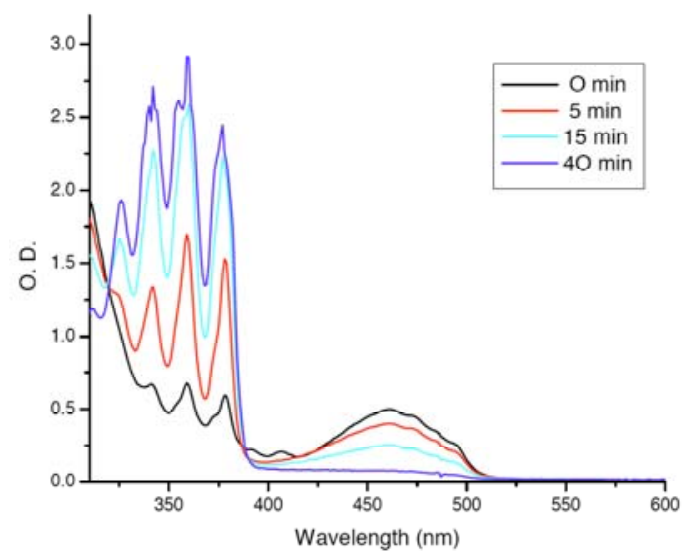

Fig. S4. Changes in UV-vis absorption spectra during irradiation of $\mathbf{1 0}$ in toluene.

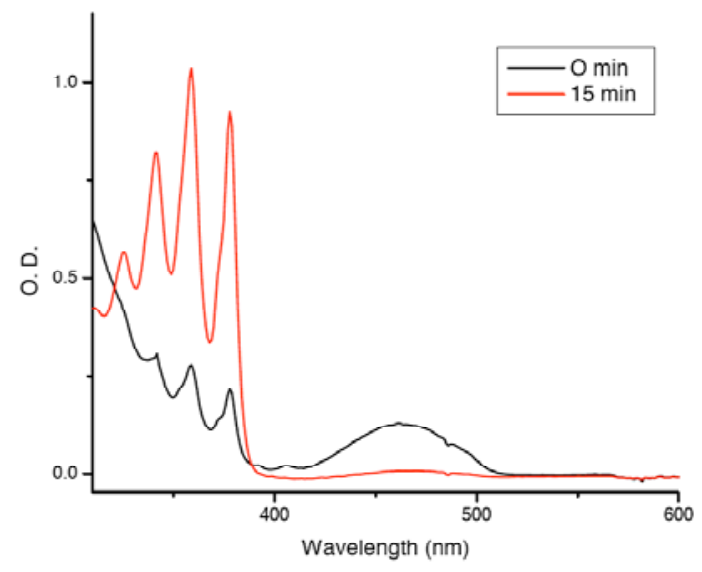

Fig. S5. Changes of UV-vis absorption spectra during irradiation of $\mathbf{1 0}$ in a PMMA film.

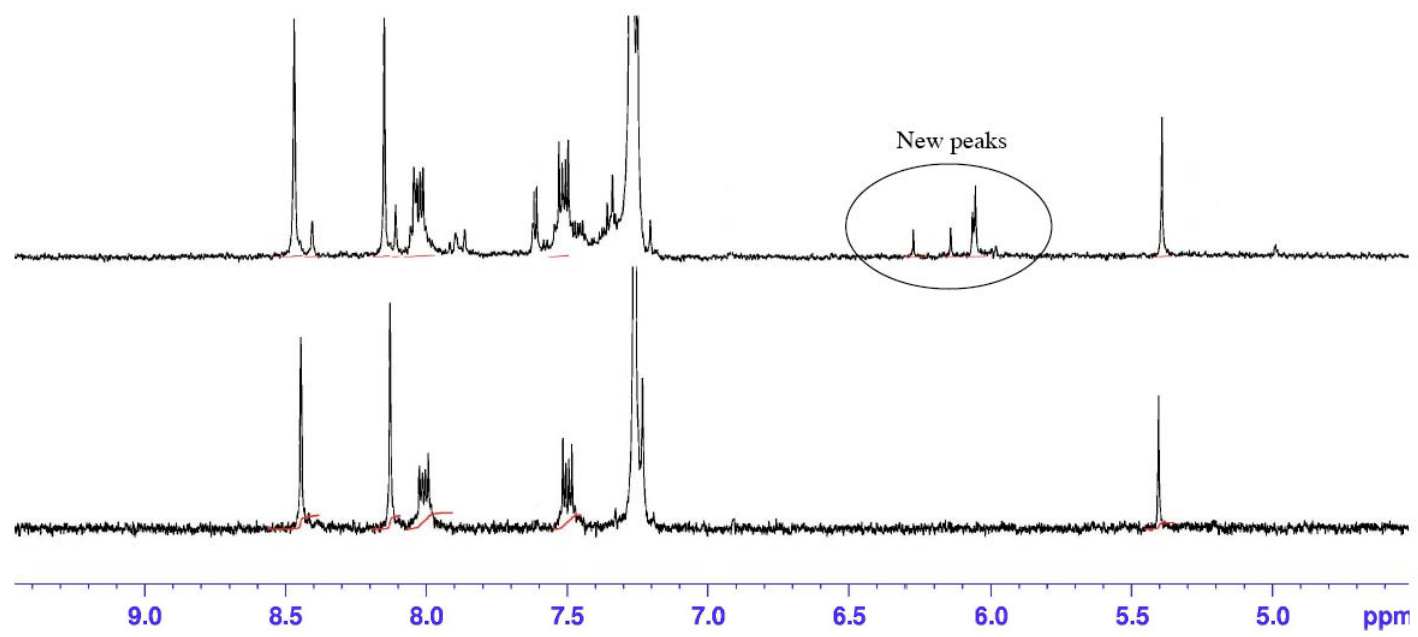

Fig. S6. ${ }^{1} \mathrm{H}-\mathrm{NMR}$ spectra of 2 before irradiation (bottom,) and after 15 min irradiation. (top) in $\mathrm{CDCl}_{3}$ purged with oxygen. 


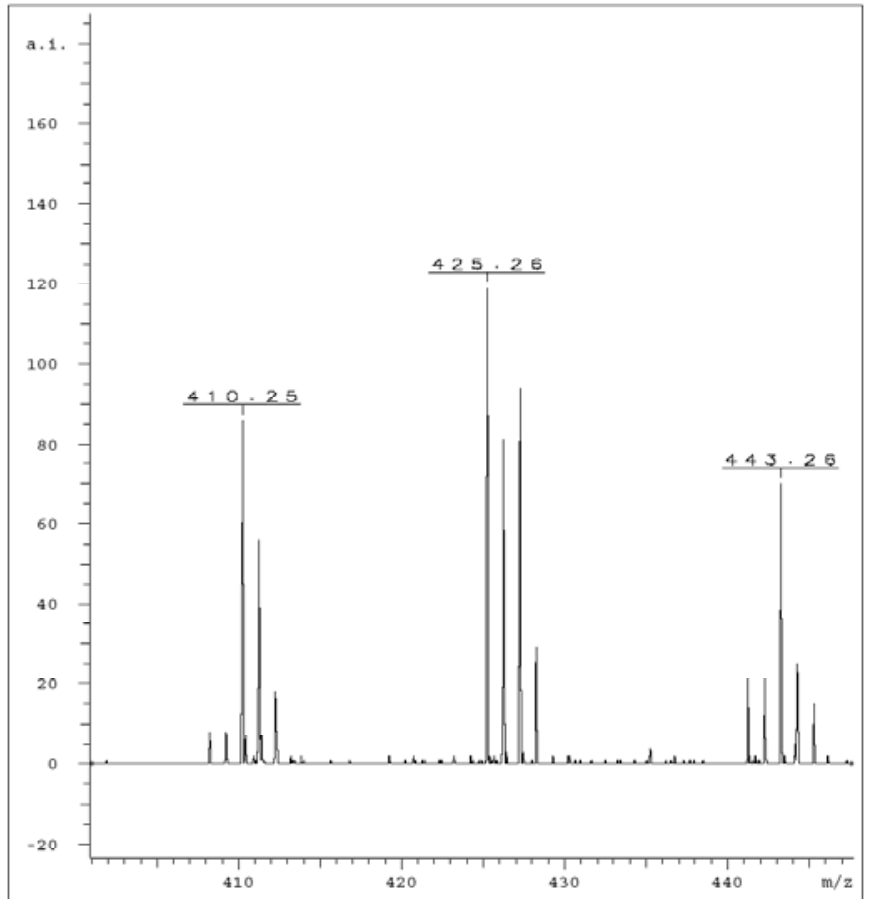

Fig. S7. MALDI-MS spectrum recorded after irradiating 2 for $15 \mathrm{~min}$. in $\mathrm{CDCl}_{3}$ purged with oxygen.

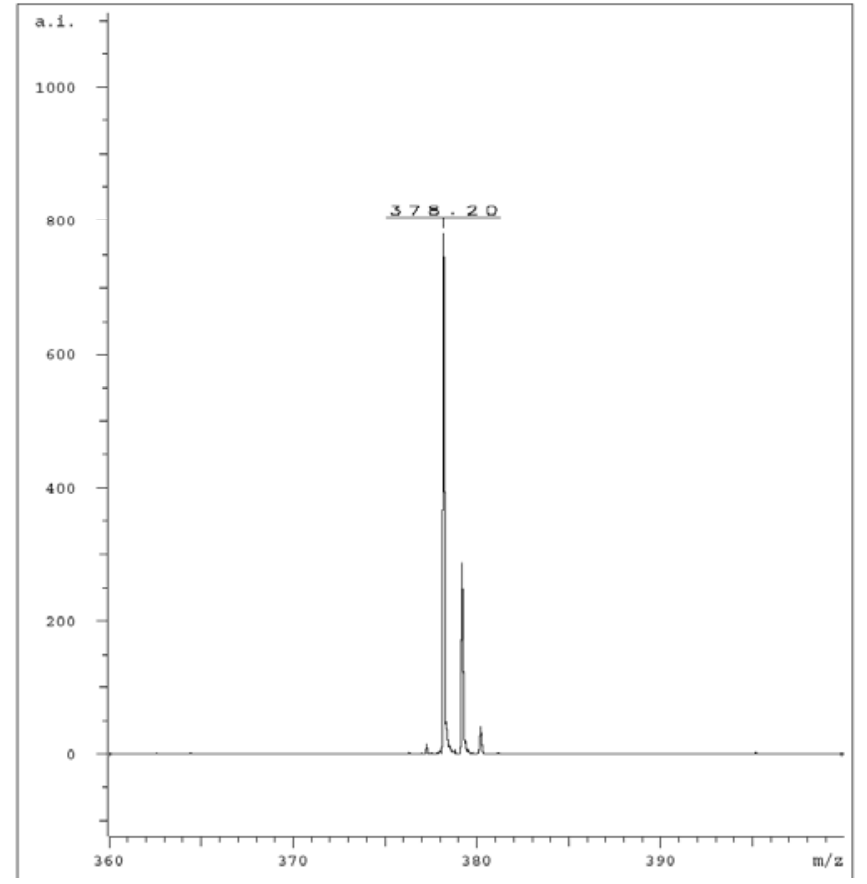

Fig. S8. MALDI-MS spectrum of 1 obtained from a thin film of PMMA. 


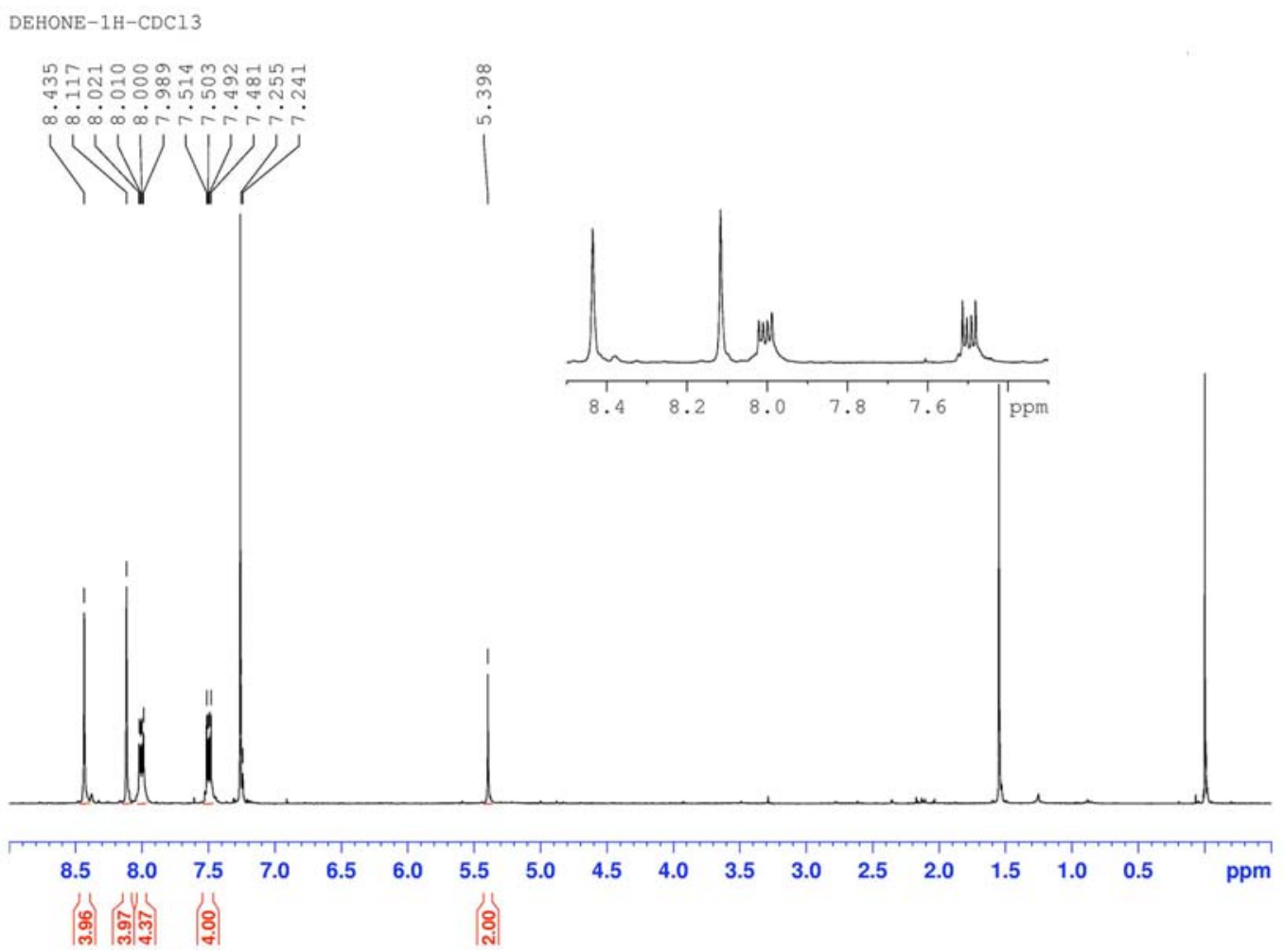

Fig. S9. ${ }^{1} \mathrm{H}-\mathrm{NMR}$ spectrum of 2.

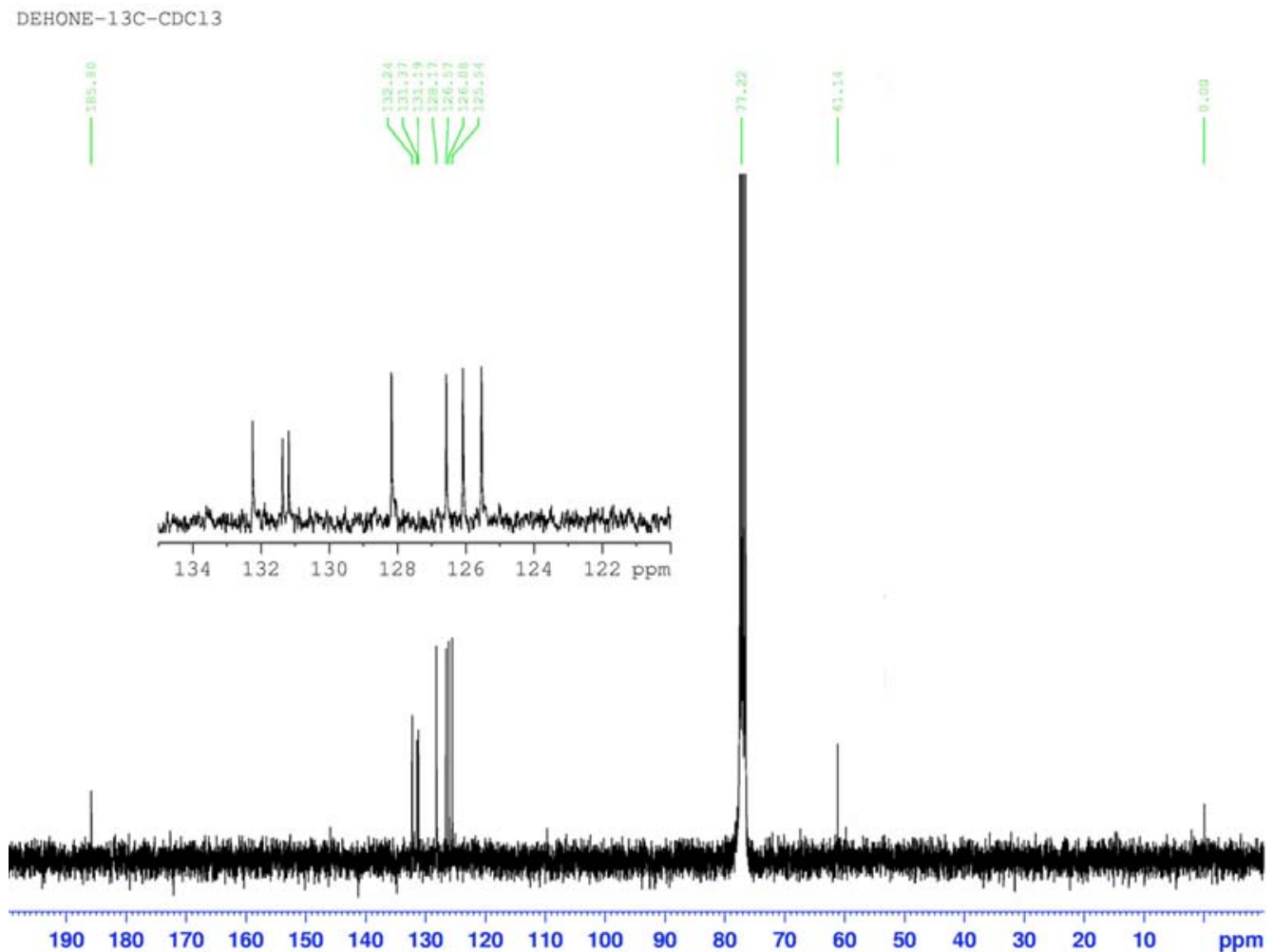

Fig. S10. ${ }^{13}$ C-NMR spectrum of 2. 